\title{
¿NEMO PRAECISI COEGIT AD FACTUM"? REINTERPRETACIÓN DESDE LA TUTELA EJECUTIVA EFECTIVA DE LAS OBLIGACIONES NO DINERARIAS
}

['Nemo Praecisi Coegit ad Factum'?

Reinterpretation of Non-Financial Obligations From the Actual Executive Protection Perspective]

\author{
Álvaro PÉREZ RAgONE* \\ Pontificia Universidad Católica de Valparaíso
}

\begin{abstract}
RESUMEN
Abstract

Desde los orígenes del derecho occidental, ya en el derecho romano, existió una preocupación por el incumplimiento de las obligaciones y la pretensión de su cumplimiento específico, en orden a solicitar a los tribunales de justicia la condena del deudor a tal cumplimiento. Adicionalmente estaba el problema de poderse ejecutar coercitivamente la pretensión de cumplimiento específico.

Palabras Clave

Cumplimiento específico - Ejecución in natura - Tutela específica.

From the origins of the western law, even in Roman law, there was concern for failing to meet obligations and for the aspects intended to ensure the specific performance of them in order to request the courts of justice to order the debtor to comply. There was also the issue that the intended specific performance could be enforced.

\section{KEYWORDS}

Specific performance - Execution in natura-Specific protection.

RECIBIDo el 6 de julio y ACEPTADo el 22 de diciembre de 2014

* Profesor de derecho procesal civil de la Pontificia Universidad Católica de Valparaíso. Dirección postal, Facultad de Derecho, Pontificia Universidad sidad Católica de Valparaíso, Casilla 4059, Valparaíso, Chile. Correo electrónico, alvaro.perez@ucv.cl. Este trabajo hace parte del proyecto interno de la Pontificia Universidad sidad Católica de Valparaíso DI Regular 37/2014, "Ejecuciones no dinerarias, Tutela de la pretensión específica”.
\end{abstract}




\section{INTRODUCCIÓN}

1. ¿Puede el deudor ser obligado a cumplir con su obligación? El acreedor confía que el deudor cumplirá y cuando ello no sucede el ordenamiento debe proveer alguna solución. Con ello surge la interrogante si el acreedor puede concretamente obligar al deudor al cumplimiento de la obligación; claro que en los casos donde es de contenido pecuniario no existe dificultad en que el acreedor pueda satisfacerse en su crédito con las alternativas que el mercado provee (el propio patrimonio del deudor). La dificultad surge cuando la obligación no puede ser cumplida sino sólo por el deudor (prestación conductual); o si se quiere el interés del acreedor no es determinable en tanto su afección en dinero, ante este supuesto ¿debe el acreedor renunciar al cumplimiento de su prestación y contentarse con la reparación pecuniaria? Dos principios jurídicos fundamentales se enfrentan, por un lado el del efecto vinculante de los contratos (con la buena fe contractual) y por el otro el de la libertad personal del deudor. A lo largo de la historia se desarrollaron en el ámbito de las prestaciones contractuales especialmente dos formas de satisfacción del acreedor las que compiten y concurren en algunos casos unas con otras: el cumplimiento in natura o específico y el cumplimiento pecuniario o por equivalente ${ }^{1}$.

Con cumplimiento específico o natural se hace referencia a que las partes cumplan su prestación primaria en la forma en la cual lo convinieron, es decir, con el exacto contenido esperado y acordado ${ }^{2}$; denominado en el sistema anglosajón "specific performance"3, ésta, pues, tiene por objeto la satisfacción del interés del acreedor mediante la prestación y su cumplimiento en sí misma ${ }^{4}$. De esta forma el acreedor recibe aquello que de acuerdo a la relación obligacional debía recibir y no un sustituto fundado en el valor económico de la prestación a través de una reparación pecuniaria ${ }^{5}$. El anteproyecto de Código Civil alemán hablaba de cumplimiento natural; y la exposición de motivos del código finalmente aprobado trataba como sinónimos al cumplimiento natural y el real ${ }^{6}$. El cumplimiento in natura se corresponde con el cumplimiento primario. La pretensión se canaliza a través de una acción

${ }^{1}$ Association Capitant (editor), Termnologie contractualle commune (Paris, 2008), p. 88.

${ }^{2}$ Rienm, Thomas, Der Grundsatz der Naturalerfüllung (Tübingen, 2014), pp. 2540.; Remien, Oliver, Rechtsverwirklichung durch Zwangsgeld (Tübingen, 1992), p. 1.

${ }^{3}$ Himmelschein, Jury, Erfüllungszwang und Lehren von den positiven Vertragsverletzungen, en Archiv für die Zivilistische Praxis, 135 (1932), pp. 255-258.

${ }^{4}$ JаковS, Horst, Unmöglichkeit und Nichterfüllung (Bonn, 1969), p. 227.

${ }^{5}$ STÖсKLI, Hubert, Synallagma im Vertragsrecht (Zürich, 2008), p. 237.

${ }^{6}$ Mugdan, Benno, Die gesammten Materialien zum Bürgerlichen Gesetzbuch für das Deutsche Reich (Berlin, 1899), II, p 110 
condenatoria para obtener una condena de cumplimiento real o natura ${ }^{7}$; finalmente relacionado con la posibilidad de la concretización ejecutiva de la condena al cumplimiento natural o real se habla de ejecución natural o real ${ }^{8}$.

Con esta introducción se aclaran los términos de cumplimiento, condena y ejecución natural; a ello hay que agregar otros tres términos a tener en cuenta: cumplimiento, condena y ejecución pecuniaria. En este caso se entienda que el interés del acreedor puede ser satisfecho mediante una suma de dinero; es decir, el cumplimiento del contrato se consigue mediante un equivalente pecuniariamente traducible para la reparación de los perjuicios, que sustituye al cumplimiento real o natural: reparación de perjuicios en lugar de cumplimiento o reparación del interés positivo como contenido en lugar de cumplimiento natural o específicio?. Es importante tener en cuenta la lealtad contractual por un lado y por otro el de la buena fe contractual, la lealtad contractual se integra con el efecto vinculante de los contratos. Por ello corresponde decir que el principio de cumplimiento in natura o la posibilidad de satisfacción del acreedor en su propio interés, en tanto cumplimiento del contrato y satisfacción natural no es, sino finalmente el cumplimiento según lo pactado o el cumplimiento de acuerdo al estándar de lealtad.

2. Como objetivo general este artículo persigue tratar la tutela ejecutiva de la pretensión específica (o in natura) tanto en lo general como en lo particular (sea su ámbito contractual o extracontractual). Como objetivo específico primero (qué) se parte de la necesidad de la adecuación de la regulación procesal para que resguarde adecuada y flexiblemente el mejor interés del acreedor en la ejecución con el respecto del principio de proporcionalidad que la posición del deudor implique. El objetivo específico segundo (para qué) es exponer la necesidad de tutela ejecutiva de nuevos derechos (contractuales, ambientales, consumidores, familia, no discriminación, laborales), que no admiten sino un flexible reconocimiento del mejor interés del acreedor (sea para una satisfacción específica in natura, específica, restitutiva o sustitutiva y no excluyente sino complementaria por equivalente (resarcitoria) ${ }^{10}$. Finalmente como objetivo tercero (cómo) se aspira demostrar desde el derecho comparado la sustentabilidad de un sistema mixto (con las mejores herramientas sustantivos procesales de la tradición del "civil law" como del "common law") en relación a las obligaciones no dinerarias y propugnar una adecuada regulación

${ }^{7}$ Himmelschein, cit. (n. 3), p. 255.

${ }^{8}$ STÖCKLI, cit. (n. 5), p. 237.

${ }^{9}$ KNÜTEL, Christian, Die Schwächen und der "konkreten" und "abstrakten" Schadensberechnung und das positive Interesse bei der Nichtserfüllung, en Archiv für die Zivilistische Praxis, 135 (2002), pp. 555-560.

${ }^{10}$ Wilhelmi, Rüdiger, Risikoschutz durch Privatrecht (Tübingen, 2009), pp. 1025. 
de la pretensión de cumplimiento específico (obligaciones positivas de hacer, dar o de declaración de voluntad o bien negativas de cese).

Baste aclarar estos puntos como estado actual y usual de tratamiento del tema: $i$ ) En la visión tradicional del derecho romano y francés (artículo 1242 inciso $3^{\circ} \mathrm{CCFr}$.), que, por cierto, influencia a otros sistemas jurídicos, el cumplimiento específico es un límite con respecto a la persona del deudor y la voluntad del acreedor. Este límite es, obviamente, inconcebible para las obligaciones dinerarias: en teoría es siempre posible obtener el cumplimiento específico, con la realización forzosa de los bienes del deudor; ii) Sin embargo, se evita que el deudor de una obligación de hacer o no hacer o cese pueda ser sin más coaccionado o ejecutado para su cumplimiento (ejecución directa). Sólo una restricción indirecta, que en relación al deudor implica mutación en una obligación dineraria es siempre vista como posible: se hará a su costa por el acreedor o de un tercero (ejecución indirecta); iii) Pero en cualquier caso, no siendo fungible la conducta requerida del deudor y si se negare a ejecutar, podría en definitiva ser condenado al pago de daños y perjuicios en compensación por su fracaso. Así el objetivo general de este proyecto es coherente con las hipótesis de las cuales se parte, poder obtener los resultados esperados y las proyecciones planteadas.

Esta contribución se divide en las siguientes partes, en primer lugar se plantean las hipótesis y los puntos de partida para el tratamiento del tema (II); en segundo lugar se realiza una breve revista histórica sobre el desarrollo y la visión en torno al cumplimiento por equivalente y aquel in natura (III); se continúa con una reflexión en torno a la visión del tema en la familia jurídica del "common law" y del "civil law" (IV); finalmente se plantea el dilema y se propone una posible solución (V) a la que se acopla las conclusiones finales (VI)

\section{HIPÓTESIS Y PUNTO DE PARTIDA}

En general el acreedor tendría el "derecho" (ya en el artículo 1142 CCFr., con amplia influencia en el sistema del "civil law") para obligar al deudor a cumplir con la obligación contractual estipulada. Ello permitiría sustentar una flexibilidad y rol decisorio discrecional del juez para escoger y otorgar lo que corresponda caso a caso. Especialmente relevante se tornaría este postulado hipotético en la tutela ejecutiva de ese derecho frente a un deudor que no quiere cumplir. Si las alternativas son tales (es decir, todas en un mismo nivel para elección del acreedor y decisión del juez) pues debiera éste aplicar un examen de razonabilidad o proporcionalidad en sentido amplio para sopesar 
la mejor alternativa para el acreedor con menor perjuicio para el deudor ${ }^{11}$. En ese contexto es posible: $i$ ) que nuevos derechos en el siglo XXI, sean en la relación contractual, sea en la extracontractual (lo suyo en la responsabilidad civil), sean categorías inútiles y finalmente diluidas en tanto se pretendan tutelar por el proceso ejecutivamente; $i$ ) que sin un cambio de paradigma procesal en la tutela ejecutiva muchos intereses como los difusos, colectivos, individuales homogéneos en una relación contractual, en las relaciones de familia, derecho ambiental, derecho de los consumidores, derecho laboral queden hipo-tutelados; iii) que el régimen tradicional de la tutela ejecutiva por resarcimiento no sea ni la alternativa primaria, ni la secundaria, sino una más a escogerse según los intereses en juego del acreedor y deudor, primando en la ejecución los del primero ${ }^{12}$.

\section{Punto de partida.}

La mayoría de los sistemas jurídicos vigentes hoy en día estarían contestes en que, al momento de la ejecución la responsabilidad no se traduce hoy solo y necesariamente en una condena a pagar daños y perjuicios. Ni siquiera se podría sustentar lo contrario en base a argumentos de eficiencia y eficacia económica. La restricción a partir del deudor se fundaría en la razonabilidad de satisfacer el interés del acreedor en el caso concreto por sobre la razonabilidad en el respeto del interés del deudor: $i$ ) adecuación entre el interés a satisfacer del acreedor con la conducta exigida al deudor; ii) Necesidad (imposibilidad) del deudor para cumplirla; iii) que sea soportable (proporcionalidad) al deudor la solución deseada, adecuada y posible del acreedor ${ }^{13}$. A partir de un examen dogmático-histórico es posible encontrar una visión que sustente el resguardo del mejor interés del acreedor mediante su tutela específica o las otras pero en equivalencia de alternativas para el requirente como para el tribunal; uno de análisis jurídico-económico-ético de las mejores alternativas para ofrecer la mejor solución sustentada que permitirá constatar positiva o negativamente las hipótesis y desarrollar ya críticamente el objetivo general como los específicos.

\section{Los intereses enfrentados de deudory acreedor en la ejecución no dineraria.}

${ }^{11}$ Weller, Marc-Philippe, Die Véase tragstreue (Tübingen, 2009), pp. 30-33; RieHM, Thomas, cit. (n. 2), pp. 15 ss.

${ }^{12}$ Weller, Marc-Philippe, Die Struktur des Erfüllungsanspruches im BGB, common law und DCFR-Ein kritischer Véase gleich, en Juristen Zeitung (2008), p. 764 ss.

${ }^{13}$ Kovac, Mitja, Comparative Contract Law And Economics (Camberley, 2011), pp. 10-25; comp. Parisi, Francesco - Cenini, Marta - Luppi , Barbara, Enforcing Bilateral Promises, A Comparative Law and Economics Perspective (Minnesota, 2014), pp. 1-5. 
El contrato pasa desapercibido en su dinámica normal (cumplimiento). Por el contrario, resuena cuando se incumple, produciendo la consecuente insatisfacción del interés del acreedor. Ello se verifica igualmente en el orden de la excepción del curso de las cosas cuando se genera un daño aquiliano, o ante su eventualidad en una visión amplia de la responsabilidad civil preventiva ${ }^{14}$. En ambas hipótesis (contractual o extracontractual o en la visión tradicional del "incumplidor" vs. el "responsable") surge la interrogante sobre si, siendo posible restituir las cosas a un estado anterior o dando al acreedor lo que específicamente solicita para la satisfacción de su interés, podría exigirlo; o si, por el contrario, la opción la tiene el deudor para, y en definitiva si él lo quiere todo se resuelva en equivalente pecuniario ${ }^{15}$. Claro que no se aprecia mayor problema si estamos frente a una obligación dineraria o de dar una cosa genérica ${ }^{16}$. Sí lo representa cuando el objeto de la prestación del acreedor es una conducta requerida del deudor en tanto un hacer, un cese de conducta, la prohibición de un hacer o la entrega de una cosa determinada ${ }^{17}$. Aquí el interés de ese acreedor es específico y sería cuestionable si puede o no ser satisfecho in natura o "específicamente", más si debe acudirse a la ejecución frente a la reticencia del deudor.

En los antecedentes históricos del derecho romano, el derecho medieval, la edad moderna y la industrialización es posible identificar una preocupación en torno al incumplimiento y a la pretensión de cumplimiento específico desde el punto de vista sustantivo. Es decir, si el acreedor titularizaba o no el derecho para exigirlo, como así también desde el punto de vista procesal, es decir respondida afirmativamente la primera interrogante cabía pregun-

${ }^{14}$ Weller, Marc-Philippe, cit. (n. 11), p. 34.

${ }^{15}$ Según el tipo de remedio existente, que no se confunde con la técnica procesal para su tutela, véanse, Pizarro Wilson, Carlos, Hacia un sistema de remedios al incumplimiento contractual, en GuZMÁN BRITo, Alejandro (editor), Estudios de Derecho Civil (Santiago, 2008), III, pp. 397-398; Meagher, Rodderick - Gummow, William - Leahne, John, Equity, Doctrine and Remedies (4a edición, Londres, 2009), \$\$20005/020; Andrews, Neil - Clarke, Malcolm - Tetenborrn, Andrew - Virgo, Graham, Contractual Duties, Specific Relief, The Grant of Specific Performance (Londres, 2011), pp. 541-598; Smits, Jan - HaAs, Daniel - Hesen, Geerte, Specific Performance in Contract Law, Nacional and other Perspectives (Portland, 2008); SprY, Ian, The Principles of Equitable Remedies ( $8^{\mathrm{a}}$ edición, Londres, 2010), pp. 340 ss.; KREITNER, Roy, Multiplicity in contract remedies, in comparative remedies for breach of contracts (Oxford, 2005), pp. 19-49.

${ }^{16}$ Peñailillo Arévalo, Daniel, Obligaciones. Teoría general y clasificaciones. La resolución por incumplimiento (Santiago, 2003), pp. 400-419; Gómez PomaR, Fernando, El incumplimiento contractual en el derecho español, en Revista para el análisis del Derecho, InDret, 3 (2007), p. 15.

${ }^{17}$ Comp. Moreno Quesada, Problemática de las obligaciones de hacer, en Revista de Derecho Privado (1976), pp. 467-502. 
tarse si el acreedor podía solicitar a los tribunales de justicia se condene al deudor al cumplimiento específico ${ }^{18}$. Otro interrogante adicional a estos dos es el relacionado con las normas procesales de ejecución, ello es si podía ejecutarse la pretensión de cumplimiento específico coercitivamente. Para este interrogante de cómo se van aclarando y especificando las dudas en concreto la pregunta gira en torno a si es posible manu militari obtener el cumplimiento específico. La respuesta no es uniforme pues si estamos frente a una obligación propiamente de dar o de entregar una cosa, la ejecución puede hacerse coercitivamente con uso de la fuerza pública obteniendo la costa del obligado o expulsando a este del bien inmueble que ocupa ${ }^{19}$, mientras que ello no es fácilmente sostenible en una obligación de hacer.

El problema en realidad se concentra en las obligaciones de hacer propiamente tales como las de realizar determinada conducta donde conviene distinguir si solo es una declaración de voluntad (fácilmente subrogable por el juez) o un hacer que puede ser fungible o no fungible. Esto para ver si esa conducta podría ser obtenida de un tercero en el mercado previa conversión de la obligación original del deudor ejecutado en una obligación de provisión de fondos, es decir una obligación dineraria. Si por el contrario la persona del deudor ejecutado es la única que podría llevar adelante esa conducta prestacional, no pudiendo ser fungible estamos frente a un supuesto en el cual no cabe la ejecución directa y habrá que analizar si existen o no medidas de auxilio, coercitivas para intentar obtener la conducta requerida antes de renunciar a ello y satisfacerse con la reparación en pecunia. Algunos sistemas permiten la ejecución indirecta mediante el empleo de medidas coercitivas que tiendan a doblegar la voluntad reticente del ejecutado para la obtención del cumplimiento de la prestación en especie (en tanto mayor abanico o menor de medios de medios de coerción ${ }^{20}$.

En el caso de las obligaciones de hacer (in faciendo) el cumplimiento en especie pone al ordenamiento jurídico frente a un dilema cual es, poner a disposición del acreedor mecanismos que garanticen y coadyuven al cumplimiento de la palabra empeñada, o bien, renunciar a ello ya que se considera más valiosa la libertad del deudor ${ }^{21}$. El intento de respuestas se debe analizar a nivel sustantivo como a nivel procesal y en este último caso ver en especial las normas relativas a la ejecución ya que, independiente de si sustantiva y/o procesalmente estamos frente a una obligación que surge de un contrato o bien de una fuente diferente a este, frente al caso de incumplimiento de una

\footnotetext{
${ }^{18}$ Weller, Marc-Philippe, cit. (n. 11), p. 109

${ }^{19}$ Ibíd., p. 110

${ }^{20}$ Ibíd., p. $110-112$

${ }^{21}$ Ibíd., p. 111
} 
sentencia condenatoria las vías y alternativas ejecutivas serán en definitiva más o menos efectivas ${ }^{22}$.

\section{BREVE REVISTA HISTÓRICA DEL PROBLEMA}

\section{Derecho romano.}

En el derecho romano predominó la condena pecuniaria, que tuvo su origen en el procedimiento formulario y que fue luego recibida por el emperador Justiniano en el procedimiento de la cognición extraordinaria. Inicialmente la visión de la obligatio se enmarcó en un marco de necesidad y sujeción del deudor donde primaba su responsabilidad sobre el deber prestacional, de forma que el cumplimiento in natura no estaba tan alejando de la concepción del vínculo y sus consecuencias. La única constitución de Justiniano que hace referencia al cumplimiento en especie se nos conserva en Cod. Iust. 7,4,17, aunque como veremos parece que tal afirmación deba ser tan absoluta. El principio de condena pecuniaria en su versión clásica aparecer en las Institutiones de Gayo del siglo II d. C. ${ }^{23}$. Justamente en el sentido expresado por Gayo es posible leer e interpretar el principio sentado por Celso en Dig. 42,1,13,124. En el mismo sentido aún cuando su disposición es excepcional cabría la mención del Dig. 6,1,68 en relación a la posibilidad manu militari para obtener mediante ella la obtención de la cosa que le es debida al demandante ${ }^{25}$. Si bien ello se debió a que en el período postclásico la creciente inflación e inestabilidad económica hacía imposible acudir a una condena pecuniaria, prevaleciendo la condena en especie o natura ${ }^{26}$. El caso es que esta mención al digesto no fue interpolada por los compiladores

${ }^{22}$ Ibíd., p. 112

${ }^{23}$ Véase al respecto los antecedentes y detalle de esta interpretación inicial en Schulz, Fritz, Classical Roman Law (Oxford, 1951), pp. 785-787. Así puede leerse en Gai. 4,48 lo que continuó teniendo vigencia en el derecho de Justiniano, "Omnium autem formularum, quae condemnationem habent, ad pecuniariam aestimationem condemnatio concepta est". Conf. con KASER, Max, Römisches Zivilprozessrecht (München, 1966), p. 238.

${ }^{24}$ Véase Savigny, Friedrich Carl von, System des heutigen römischen Rechts (Berlin, 1840-1849), V, $\$ 215$, p. 75; en este sentido Véase Dondorp, Harry, Specific Performance, a Historical Perspective, en Smits, Jan - HaAs, Daniel - Hesen, Geerte (editores), Specific Performance in Contract Law, National and other Perspectives (Antwerp, 2010), pp. 280-282; Weller, Marc-Philippe, cit. (n. 11), pp. $104 \mathrm{s.}$

${ }^{25}$ Véase al respecto: Sintenis, Carl Friedrich Ferdinand, Was ist Gegenstand der Klagen aus Obligationibus ad faciendum überhaupt und der action emti im Besesonderen, Zeitschrift für Civilrecht und Prozess, 11 (1838), pp. 20 y 75.

${ }^{26}$ Sohm, Rudop - MitTeis, Ludwig - Wenger, Leopold, Institutionen, Geschichte und System des römischen Privatsrechts (Berlin, 1949), pp. 692 s. 
del mismo y con ello es posible sostener que la condena pecuniaria pudo haber sido la que prevaleció como principio en el derecho de Justiniano aún cuando no haya sido adoptado el texto de las Institutiones de Gayo 4,48. Con ello puede sostenerse que ni siquiera el texto de Dig. de 42,1,13,1 contiene evidencia de que el único principio haya sido el de la condena pecuniaria, aunque sí el prevalente. Ello ya que este regula un supuesto muy especial relacionado con la estipulación y no con las obligaciones en general, no quedando claro en este caso si el acreedor podía demandar solamente la reparación de perjuicios o algo más ${ }^{27}$.

\section{Derecho medieval y moderno.}

Los juristas medievales encontraron en el Corpus iuris civilis sustento suficiente para sostener que bajo el derecho de Justiniano era posible demandar y obtener el cumplimiento específico. Las Institutiones de Justiniano por ejemplo $(4,6,32)^{28}$ no excluyen el cumplimiento de las sentencias in natura o en especie. El problema para los juristas medievales no fue si la legislación de Justiniano estaba familiarizada o no con el cumplimiento específico y la posibilidad de ejecución en tal sentido, sino más bien en cuáles casos específicos se podía demandar y obtener una condena in natura que luego pudiera ser ejecutada en tal sentido. En Dig. 42,1,13,1 se describe la situación relacionada con las obligaciones de hacer algo, siempre y cuando ello no pueda ser realizado en especie por un tercero ${ }^{29}$. Cabe mencionar aquí la Glossa de Accursio fortalecida posteriormente en la opinión prevaleciente en los días de Bartolo de Saxoferrato al menos en relación a las obligaciones contractuales. Se sostenía así que las obligaciones de hacer impuestas por una disposición del Corpus y que no hayan sido voluntariamente asumidas mediante un contrato eran ejecutables en especie, lo mismo era aplicable también a las obligaciones que resultaban de declaración unilaterales de última voluntad. De esta forma no resultaba aplicable la ejecución in natura o en especie solo para aquellos supuestos contractuales en los cuales la prestación no podía ser cumplida mediante un tercero. Esta visión de Bartolus fue influyente en la costumbre itálica fundándose en que cuando el deudor está en mora,

${ }^{27}$ WAGNER, Gerhard, Ansprüche auf Unmögliches? en Juristen Zeitung (1998), pp. 482-485.

${ }^{28}$ RePGen, Tilman, Von tragstreue und Erfüllungszwang in der mittelalterlichen Rechtswissenschaft (Padderborn, 1994), p. 30.

${ }^{29}$ Ibíd., p. 30-32; RÜCKERT, Joachim, Leistungsstörungen und Juristenideologien heute und gestern. Ein problemgeschichtlicher Beitrag zum Privatsrecht im Europa, EN Festschrift Kilian (Baden-Baden, 2004), pp. 705-710, 730. 
la obligación de hacer continúa existiendo, pero paralelo a ella surge una alternativa de obligación en interés del acreedor ${ }^{30}$.

En el Corpus iuris civilis y en torno a la jurisprudencia conformada entre los siglos XI a XVI el principio de cumplimiento in natura fue objeto de importantes controversias. En primer lugar se diferenciaba entre las obligaciones de dar y las obligaciones de hacer obligaciones in dando y obligaciones in faciend $o^{31}$ respectivamente. La mayoría de las obligaciones de dar podían ser exigibles por el acreedor y regía para el demandado la obligación de estar al cumplimiento preciso, ${ }^{32}$ así se infería de un pasaje de Ulpiano ${ }^{33}$ que el deudor podía ser obligado coactivamente en el caso que deba hacer entrega de una cosa la que podía ser tomada en la ejecución mediante la fuerza por el órgano ejecutor para entregársela al acreedor ${ }^{34}$. Era discutible al respecto en el contrato de compraventa la posibilidad de cumplimiento natural o específico que recién con las glosas y los comentarios de Bartolo terminó primando la visión de que la demanda del comprador era calificable como una obligación de dar ${ }^{35}$.

En el caso de las obligaciones de hacer las distintas posiciones se manifestaban a favor, sea del cumplimiento pecuniario, sea in natura. Especialmente se discutía si el promitente de una obligación de hacer podía ser obligado o si quedaba liberado mediante la satisfacción del interés positivo previa reparación pecuniaria ${ }^{36}$. Los comentadores entre los siglos XIII a XVI terminaron por minimizar el impacto e importancia del principio de cumplimiento natura ${ }^{37}$. El deudor tenía la libertad para decidir si el satisfacía el interés del acreedor en forma natural o mediante reparación pecuniaria. Ello se asienta en la doctrina del principio del cumplimiento por equivalente pecuniario bajo la influencia fuerte de Baldo en relación a las obligaciones de hacer corrigiendo la premisa y sosteniendo con corrección de las tesis radicales que era permisible el cumplimiento in natura en algunos $\operatorname{casos}^{38}$.

\footnotetext{
${ }^{30}$ Dilcher, Hermann, Die Theorie Leistungsstörungen bei Glossatoren, Kommentatoren und Kanonisten (Frankfurt a. Main), pp. 119-122.

${ }^{31}$ Dilcher , Hermann, Geldkondemnation und Sachkondemnation in den mittelalterlichen Rechtstheorie, en Zeitschrift der Savigny-Stiftung für Rechtsgeschichte, Rom. Abt., 78 (1961), pp. 277-280.

${ }^{32}$ ZimmermanN, Reinhard, Law of Obligations (Oxford, 1996), pp. 773-775.

${ }^{33}$ Nehlsen von Stryx, Karin, Grenzen des Rechtszwangs, Zur Geschichte der Naturalvollstreckung, en Archiv für die Civilistische Praxis, 193 (1993), pp. 529-538.

${ }^{34}$ Dilcher , cit. (n. 31) pp. 277-279 y 284.

${ }^{35}$ RePGen, cit. (not. 28), pp. 107 y 321.

${ }^{36}$ Dilcher, cit. (n. 30), pp. $120 \mathrm{~s}$.

${ }^{37}$ REPGEN, cit. (not. 28), pp. 52 y 65-80.

${ }^{38}$ ZimmermanN, cit. (n. 32), p. 773.
} 


\section{Derecho canónico y natural: excomunión y condena "ex canone".}

La pretensión de cumplimiento específico del acreedor vino a ser reconocida aunque en forma indirecta por el papa Inocencio IV al establecer la alternativa (canónica) paralela a la demanda de cumplimiento natural, la denominada denuncia evangélica ${ }^{39}$. De forma tal que la vulneración a la promesa y a la lealtad de cumplimiento es considerada un pecado que podía ser sancionado con la excomunión, ello a partir de un procedimiento contumacial en el cual el juez eclesiástico decidía sobre los medios de coerción fundándose en la amenaza de excomunión para obtener el cumplimiento natural o específico. Hasta el siglo XV inclusive rigió esta visión del cumplimiento inmediato de toda promesa o pacto de obligación de hacer. La pretensión de cumplimiento in natura o natural vendrá garantizada a través de la condición canónica ${ }^{40}$ la que por su lado permitía una condena en especie y/o in natura. Aún cuando no podía hacérsela valer por los tribunales o por ante los tribunales seculares, tuvo impacto y era reconocida en ámbitos importantes de la sociedad dando pues plenos efectos a la competencia eclesiástica ${ }^{41}$. Así por ejemplo los comerciantes y clérigos se sometían a ella, de esta forma el derecho canónico otorga al acreedor la posibilidad de exigencia del cumplimiento in natura en relación a todo tipo de obligaciones ${ }^{42}$.

En el derecho natural rige en las obligaciones de hacer el principio del cumplimiento por equivalente pecuniario ${ }^{43}$. lo que se manifiesta en el $\mathrm{Co}$ dex Maximilianeus Bavaricus Civilis de 1756 donde se distingue entre las obligaciones de dar y las obligaciones de hacer, pudiendo el deudor liberarse en el caso de estas últimas mediante la satisfacción pecuniaria del interés del acreedor ${ }^{44}$. Un mecanismo similar será el que se reconocerá por el Code Civil de 1804 en su artículo 1142 según el cual en las obligaciones de hacer, en caso de incumplimiento se transforma en deberes secundarios, ello es la satisfacción o el deber de cumplimiento pecuniario de la obligación. Detrás de ello rige el pensamiento de que el cumplimiento por equivalente pecuniario

${ }^{39}$ Ello con fundamento en el Evangelio de San Mateo 18,15-17. Véase al respecto en detalle: SöLlner, Alfred, Die causa im Kondiktionen- und Véase tragsrecht des Mittelalters bei den Glossatoren, Kommentatoren und Kanonisten, Zeitschrift der SavignyStiftung für Rechtsgeschichte, Rom. Abt., 77 (1960), p. 182.

${ }^{40}$ Söllner, cit. (n. 39), p. 182; STAthopoulos, Michael, Probleme der Vertragsbindung und Vertragslösung in rechtsvgleichende Betrachtung, en Archiv für die Civilistische Praxis, 194 (1994), pp. 542-547.

${ }^{41}$ Liebs, Detlev, Römisches Recht (Göttingen, 1982), pp. 218 s.

${ }^{42}$ ZimmermanN, cit. (n. 32), p. 780.

${ }^{43}$ RePGeN, cit. (n. 28), p. 328.

${ }^{44}$ Codex Maximilianeus Bavaricus Civilis (München, 1821), esp. IV, $1 \S 17$. 
como principio tiene directa relación con la intangibilidad de la libertad del hombre en el pensamiento del siglo XVIII ${ }^{45}$.

El hecho de que la obligación original todavía exista, sin embargo, fue un dato parcialmente ignorado por la doctrina española iusnaturalista del siglo $\mathrm{XVI}^{46}$. De acuerdo al derecho canónico y en especial al castellano contenido en las siete partidas, el acreedor está obligado a percibir el cumplimiento en especie en las obligaciones de hacer, en especial los escolásticos jesuitas de la segunda mitad del siglo XVI, especial mención para el cumplimiento pecuniario merece Luis de Molina como el principal jurista que discutió el tema. Éste se oponía a la idea de que el deudor de una obligación de hacer pudiera tener la opción entre pagar una suma de dinero o resarcir al acreedor, el deudor está obligado a cumplir en especie siempre que sea posible y exista la obligación. Lo único que podría inferirse de acuerdo a este autor de lo enunciado en Dig. 42,1,13,1 no era sino que el deudor moroso en su actuar, negligente por responsabilidad extracontractual funda la existencia de una opción pero en cabeza del acreedor. Quien puede optar entre el resarcimiento pecuniario, exigir y ejecutar in natura la obligación de hacer es el acreedor y no el deudor. Cuando en 1604 el magistrado francés Antoine Fabre (1557 a 1624) enunció la máxima de que nadie puede ser obligado coercitivamente a actuar "nemo praecisi coegit ad factum" ${ }^{7}$, el significado práctico de dicho principio había perdido su fuerza incluso en relación a las obligaciones de hacer. El problema del cumplimiento específico fue siempre tratar de ver cómo obtener aquello a lo cual se había obligado el deudor y así las distinciones entre obligaciones de hacer que consistían en dar o entregar una cosa no cabía duda que era posible obtener su cumplimiento en especie acudiendo a la coerción. El problema de las medidas coercitivas se centraba más bien en las obligaciones puramente de hacer cuando no eran susceptibles que sean cumplidas por terceros. Ello ya que las medidas coercitivas podían consistir en multas, sanciones pecuniarias en favor del acreedor o prisión. Lo cierto es que las leyes de Castilla preveían la posibilidad de la aplicación de prisión para los casos de incumplimiento de la servidumbre doméstica de sus obligaciones (y de las encomiendas) ${ }^{48}$. Curiosamente el mismo derecho natural sirvió de contra argumento para sostener que no era posible afectar la libertad como derecho natural habilitando el cumplimiento coercitivo y la ejecución de obligaciones de hacer, las que deberían en su reemplazo

\footnotetext{
${ }^{45}$ REPGEN, cit. (n. 28), p. 24.

${ }^{46}$ LuIG, Klaus, Wissenschaft und Kodifikation des Privatrechts im Zeitalter der Aufklärung in der Sicht vom Christian Thomasius, en Festschrift f. Helmut Coing (München, 1982), I, p. 177-189.

${ }^{47}$ Acollas, Emile, Manuel de droit civil (Paris, 1869), II, p. 720.

${ }^{48}$ RePGen, cit. (n. 28), p. 25.
} 
convertirse en obligaciones de pagar daños o de resarcimiento ${ }^{49}$. Ello fue considerado e incorporado en el artículo 1142 del Code Civil francés aunque sólo referido a las obligaciones de mero hacer.

En Francia aparte de Domat o tiene era partidario de la primacía del cumplimiento en especie o natural ${ }^{50}$. Para las obligaciones de dar enuncia que existe una posición fuerte del lado del acreedor quien siempre puede efectivizar el cumplimiento natural o en especie ${ }^{51}$. En forma inversa el deudor no puede liberarse de la voluntad del acreedor mediante la reparación pecuniaria o satisfacción de su interés ${ }^{52}$. En suma el concepto de cumplimiento in natura se acerca al de cumplimiento en especie o real del BGB. alemán donde se establece en primer lugar la pretensión de cumplimiento en especie o en natura, en segundo lugar la reparación pecuniaria del interés positivo del acreedor. En Alemania quien representara la visión del principio de cumplimiento natural o en especie será Christian Thomasius ${ }^{53}$, quien ve en el cumplimiento de las pretensiones en forma natural no sólo un elemento de diferenciación entre el derecho y la moral, sino además uno de los detalles característicos de los deberes jurídicos: la posibilidad de su cumplimiento y su exigibilidad forzosa. El principio de cumplimiento natural también tiene aplicación en el Allgemeines Landrecht prusiano de 1794, del cual el $\$ 270$ del cap. $5^{\circ}$ de la $1^{\text {a }}$ parte establece la regla del cumplimiento in natura (“[...] müssen die Verträge nach ibrem ganzen Inhalt erfüllt werden”), lo que se va a reflejar en las regulaciones procesales y judiciales de los Estados prusianos a través de la figura del oficial de ejecución de obligaciones de hacer y no hacer en los $\$ \$ 48$ y 54 respectivamente.

\section{La pandectistica alemana.}

La discusión en el derecho de las Pandectas en Alemania girará en torno a la discusión entre "deber" o "responsabilidad" como esencia de la obligación ${ }^{54}$. Así para Brinz ${ }^{55}$ este representará como esencia de la obligación a la responsabilidad y por ende la realización de los derechos subjetivos se presenta

${ }^{49}$ WeLler, Marc-Philippe, cit. (n. 11), pp. 97-98.

${ }^{50}$ Domat, Jean Les lois civile dans leur ordre naturel (Paris/Luxemburg, 1702), I, p. 24, donde enuncia que : "[...] le premier effet de la convention, est que chacun des contractants peut obliger l autre à exécuter son engagement". Comp. Con POTHIER, RobertJoseph, Traité des Obligations, en CEuvres de Pothier (Paris, 1818), III, pp. 156-158.

${ }^{51}$ Weller, Marc-Philippe, cit. (n. 11), pp. 99-100.

${ }^{52}$ Ibíd., pp. 100-101.

${ }^{53}$ RÜCKERT, cit. (n. 29), pp. 705-708 y 730.

${ }^{54}$ ZIEBARTH, Karl, Realexecution und Obligations-Mit besonderer Rücksicht auf die Miethe erörtet nach römischen und deuschtem Recht im Vergleich mit dem preussischem (Halle, 1866), pp. 23-25.

${ }^{55}$ BrInZ, Alois von, Lehrbuch der Pandekten (Erlangen, 1879), II,1, pp. 1 ss.; 
como una cuestión de hecho, ya que en caso de incumplimiento el objeto de esa prestación se presenta como un poder meramente físico y por ende debe ser reemplazado mediante el dinero. Así el cumplimiento por equivalente se caracterizaría por la posibilidad de la satisfacción del interés en base a la responsabilidad por incumplimiento. Hartman sostiene que la esencia de la obligación es el deber y por ello el cumplimiento in natura se manifiesta como el contenido primario o la pretensión primaria de las obligaciones, ya que el cumplimiento por equivalente es simplemente un subrogado que sustituye el objeto original de la obligación ${ }^{56}$. Según Savigny la libertad personal se modifica mediante la obligación, así desde el punto de vista del acreedor la libertad se amplía ya que la obligación está revestida de la posibilidad de ser exigida judicialmente; mientras que desde el punto de vista del deudor la libertad natural se limita ya que tiene un deber de cumplimiento en tanto deber de satisfacción para con el acreedor en específico o en forma natural aquello a lo cual se comprometiós7.

La diferenciación entre el derecho material y procesal será uno de los grandes aportes dentro de la Comisión redactora del BGB. alemán por parte de Windscheid quien sostiene la eliminación del derecho romano por la aplicación del derecho nacional y por ello ${ }^{58}$ comprende a la acción ya no más en el sentido que le daban los magistrados romanos. Muy por el contrario los tribunales y el ejercicio de las acciones mediante la demanda procesal insta a que estos sean servidores del derecho y todo transcurre en un proceso que contempla la posibilidad del cumplimiento forzoso y así garantiza el derecho de ejecución forzosa de las obligaciones (sentencia de condena). Coherente con ello es que se regulan en el Código Procesal Civil de 1877 las medidas de coerción desde multa hasta prisión para garantizar el cumplimiento práctico de las obligaciones in natura. Mientras más fuerte se establezca y condicione el cumplimiento in natura en la concepción del mercado más se relativiza el significado de las preguntas relativas a la ejecución, ya que la regulación será suficientemente disuasiva para incentivar el cumplimiento ${ }^{59}$. Ello ayuda a la dinámica misma del mercado. Es mucho más importante la posibilidad de

Brinz, Alois von, Obligation und Haftung, en Archiv für die Civilistische Praxis, 70 (1886), pp. 374-390.

${ }^{56}$ Hartmann, Gustav, Die Obligation-Untersuchungen über ibren Zweck und Bau (Erlangen, 1875), p. 159.

${ }^{57}$ Savigny, Friedrich Carl von, Das Obligationenrecht als Theil des heutigen römischen Recht (Berlin, 1851-1853), I, p. 1-6.

${ }^{58}$ WindsCHEID, Bernhard, Die Actio des römischen Zivilrechts vom Standpunkte des heutigen Rechts (1856, reimpresión Aalen, 1969), pp. 1-10 y 210-230.

${ }^{59}$ Windscheid, Bernhard, Die Actio-Abwehr gegen Dr. Theodor Muther (1857 reimpresión Aalen, 1969), pp. 88-99. 
poder demandar una condena de cumplimiento in natura, que la ejecución de ésta. Por un lado el principio de condena pecuniaria ya no rige por el lado de la ejecución ya que el juez de acuerdo a lo dispuesto en el código procesal civil puede exigir el cumplimiento de la sentencia mediante la aplicación de penas y medidas de coerción ${ }^{60}$.

De esta forma un deudor no puede ser personalmente compelido para el cumplimiento de cierta prestación que se centre en su conducta, lo que no impediría por ejemplo que el vendedor pueda ser coaccionado para que proceda a la entrega de una cosa. Durante el siglo XIX la idea base fue que el deudor estaba obligado a cumplir en especie y que el acreedor podía exigir su cumplimiento y ejecución ya sea en forma directa o bien indirecta. Esto se va a manifestar en el BGB. alemán donde se establece como remedio primario el cumplimiento in natura si bien no para materia comercial, sí definitivamente para lo civil ${ }^{61}$. Debe recordarse incluso que en Alemania durante el siglo XIX aún era posible exigir ciertas conductas de cumplimiento in natura o en especie con motivo de la secularización del matrimonio y de su indisolubilidad, por ejemplo siendo exigible los esponsales o el deber de contraer matrimonio ${ }^{62}$.

En el marco del desarrollo industrial puede igualmente verse que en el tráfico mercantil era mucho más ventajoso para el comprador obtener una reparación pecuniaria que exigir y ejecutar el cumplimiento de la obligación de entrega por parte del vendedor. Ya no era tan importante si se lograba o no la entrega de la mercadería, sino si la misma se entregaba oportunamente y en forma de acuerdo a lo planificado. Cuando ello no era posible y el acreedor perdía todo interés, lo más práctico era el resarcimiento y no el cumplimiento en especie. Mediante el resarcimiento pecuniario le quedaba habilitada la posibilidad para intentar adquirir la mercadería de otro proveedor en el mercado $^{63}$. No obstante ello la ZPO. alemana como así también el Código Procesal Civil francés eliminaron en el siglo XX la prisión por deudas y en su lugar se incorporaron la posibilidad de aplicación de medidas coercitivas o mecanismos de ejecución indirectos mediante la aplicación de multas ${ }^{64}$. Por su lado en el caso francés se incorporan las "astreintes" en el año 1933 al código procesal civil y que consistían en una multa o pena pecuniaria que debía ser pagada al acreedor por día de incumplimiento por parte del deudor

${ }^{60}$ WindSCHEID, cit. (n. 58), pp. 230-232.

${ }^{61}$ WindsCheid, cit. (n. 59), pp. 1 n. 1 y 25

${ }^{62}$ Véase al respecto KoHLER, Joseph, Ungehorsam und Vollstreckung im Civilproze $\beta$, en Archiv für die Civilistische Praxis, 80 (1893), pp. 141, 197.

${ }^{63}$ Windscheid, Bernhar - Kipp, Theodor, Lehrbuch des Pandektenrecht (Frankfurt a. M., 1906), II, §250, pp. 4-6.

${ }^{64}$ RePGEN, cit. (n. 28), p. 329. 
a favor del acreedor, algo similar ya había sido contemplado en el código procesal civil alemán de $1877^{65}$.

\section{LAS DOS GRANDES FAMILIAS JURÍDICAS}

El cumplimiento contractual tiene relación con la esencia del contrato ya que éstos están hechos o fueron celebrados justamente para cumplirse y es el fundamento de su formación. Podríamos decir que es el único interés existente en la relación contractual, es el interés en el cumplimiento referido a su satisfacción o el beneficio para el cual las partes se comprometieron. Es cierto que puede no hacerse inicialmente una distinción entre cumplimiento y resarcimiento o indemnización de perjuicios ya que son dos alternativas eventuales frente a las cuales se podría encontrar el acreedor y/o bien podría ofrecer el deudor ${ }^{66}$. La pregunta central es de qué manera se protege de mejor forma el interés de cumplimiento específico. En la tradición inglesa la fuerza vinculante de los contratos era muy endeble, ello por la debilidad de los remedios contractuales existentes, lo que se condice con el gran número de contratos regularmente no cumplidos ${ }^{67}$.

El juez Lord Millett señaló en el caso "Alfred MacAlpine Construction Ltd. versus Panatown Ltd.” que existe a veces un gran consenso entre los académicos en relación a que el derecho inglés adopta un indebido y restringido acercamiento en torno al concepto de daños y pérdidas en el contrato y que esto es debido al reconocimiento de que el cumplimiento de las obligaciones contractuales puede tener un valor económico por sí mismo $^{68}$. Con esto concluye Lord Millett señalando que si el defecto del derecho inglés en otorgar los adecuados remedios se desvía del interés y de las expectativas de las partes, las que lo ven como una injusticia, la culpa es precisamente por la indebida visión limitada que las Cortes emplean para el concepto de pérdida y afectación al real interés de cumplimiento in natura ${ }^{69}$. Otro importante aporte a la discusión es el propuesto por Lord Bridge en el caso "Ruxley Electronics and Construction Ltd. versus Forsyth" 70 . En él se sostiene que los daños por ruptura del contrato normalmente proceden en base a la asunción de que cada parte contratante tiene un interés meramente comercial y por ende las pérdidas resultantes del incumplimiento son men-

\footnotetext{
${ }^{65}$ Ibíd., p. 330.

${ }^{66} \mathrm{JACOB}$, Sir Jack, The Fabric of English Justice (London, 1887), p. 188.

${ }^{67}$ Comp. Zuckerman, Adrian, Civil Procedure (Oxford, 2003), núm. 22.77.

${ }^{68}$ Appeal Court, 2001, p. 518.

${ }^{69}$ Ibíd., pp. 587, 581.

${ }^{70}$ Appeal Court, 1996, p. 344.
} 
surables desde un punto puramente económico, aun cuando esta visión no sea en todos los casos la apropiada ${ }^{71}$.

Un examen adicional desde el punto de vista del análisis económico de los contratos son las teorías sobre la eficiencia y la conducta estratégica, es decir las conductas que asumen las partes para la obtención de mayores beneficios con el menor perjuicio. Se sostiene incluso el llamado incumplimiento eficiente del contrato mediante el cual la contratante examina con posterioridad que podría realizar una actividad con mayores ganancias que aquella para la cual contrató, en cuyo caso es mejor reconocerle el derecho a la ruptura e incumplimiento en base a una opción racional de carácter económica ${ }^{72}$. Así los remedios contractuales comprenden todos aquellos mecanismos disponibles para la protección del interés en el cumplimiento contractual, sea el cumplimiento específico, sean la conclusión o extinción del contrato, sea la resolución, sea la indemnización por daños, sean los daños punitivos debieran, según esta visión orientarse en términos de eficiencia ${ }^{73}$.

Por el contrario desde el punto de vista del derecho comparado puede sostenerse que el derecho francés ofrece remedios contractuales que son notoriamente más protectores del interés en el cumplimiento y que no encuentran equivalentes en el derecho inglés. En efecto el interés específico se protege de forma débil en Inglaterra y de forma mucho más fuerte en Francia. Esto lo demuestra el estudio comparativo de Laithier ${ }^{74}$ y el importante texto en el derecho inglés de remedios para el incumplimiento contractual de Treitel publicado en el año $1988^{75}$.

Es importante mencionar en su momento las importantes propuestas de modificación al derecho de las obligaciones y de la prescripción preparados por bajo la dirección de Catala en el derecho francés ${ }^{76}$ a lo que se le suma la propuesta del Ministerio de Justicia con la misma finalidad ${ }^{77}$ ambas destinadas a la modificación del Code Civil francés de 1804 en aspectos de relevancia como el derecho de los contratos, la responsabilidad civil, el enriquecimiento injustificado, la prescripción. Especialmente el "anteproyecto Catala” remarca la longevidad del Código francés que es considerado

${ }^{71}$ Ibíd., p. 353.

${ }^{72}$ Atiyan, Patrick, The Liberal Theory of Contract, en Essays on Contract (Oxford, 1988), pp. 121-124

${ }^{73}$ Treitel, Guenter, Remedies for Breach of Contracts. A Comparative Account (Oxford, 1988), passim.

${ }^{74}$ LAITHIER, Yves-Marie, Etude comparative des sanctions de Pinexécution du contrat (Paris, 2004), pp. 10-35.

${ }^{75}$ Treitel, cit. (n. 72),

${ }^{76}$ Avant-Projet de Réforme du Droit des Obligations, 2005.

${ }^{77}$ Projet de Réforme du droit des contrat, 2008. 
por muchos abogados franceses como anacrónico y consecuente con ello sostienen que declinó su influencia en el extranjero, por lo que se propone la modernización del código civil para hacerlo más atractivo y exportable internacionalmente ${ }^{78}$. Sí es posible concluir que en la tradición del derecho inglés las alternativas de protección del interés en el cumplimiento específico son menores, y las existentes se reducen al ámbito del derecho de la equidad en donde originariamente se concibieron. Primando la indemnización por daños o la tutela resarcitoria por sobre la tutela específica sustantivamente, ello luego trasunta en lo procesal.

Por su lado en el derecho francés existen mayores mecanismos de resguardo del interés en el cumplimiento específico y que sólo encuentra limitaciones en tanto se haga referencia al cumplimiento de obligaciones de hacer no fungibles o personal y que no puedan ser cumplidas por un tercero. En estas se admite solo el empleo de medidas coercitivas de carácter pecuniario como las "astreintes" para intentar doblegar la voluntad del deudor renuente a cumplir. Sí resulta interesante dentro de este contexto la inexistencia de mecanismos activos previamente contemplados por el legislador para determinar la voluntad o no de cumplimiento, y acá se incluye tanto el cumplimiento de un contrato como el respeto del deber general de no ocasionar un daño. En ambos supuestos se pueden finalmente encontrar con una sentencia condenatoria que pueda ordenar un cumplimiento específico frente al daño ocasionado diferente a un resarcimiento o reparación meramente económica. El derecho inglés sería más transparente ya que sustantiva como procesalmente el interesado sabe a qué atenerse y las posibilidades de poder o no tener un cumplimiento específico que difiera del mero resarcimiento de los daños y perjuicios que sufrió es más previsible. Por su lado el derecho francés regula sustantivamente determinadas consecuencias que pueden hacerse valer en el ámbito procesal, pero que al momento de la ejecución existe siempre la posibilidad en cabeza del deudor de ofrecer una sustitución o reemplazo pudiéndose de hecho solamente obtener una tutela resarcitoria en tanto opción última del deudor ${ }^{79}$. A ello debe sumarse la inexistencia de mecanismos tales como los daños punitivos cuya cuantía y forma de aplicación constituyen un importante instrumento disuasivo para el cumplimiento específico. Aquellos desempeñan un rol complementario a la tutela resarcitoria de exigencia de conductas específicas con la garantía

${ }^{78}$ Vogenauer, Stefan, “Avant-Projet de Réforme”. An Overview, en CARTWright, J. - Whittaker, S. - Vogenauer, S. (editores), Reforming the French Law of Obligation, Comparative Reflections (Oxford, 2009), p. 3.

${ }^{79}$ Row an, Solène, Remedies for Breach of Contract (Oxford, 2012), pp. $68 \mathrm{~s}$. 
de la posibilidad de aplicación de sanciones pecuniarias que exceden la mera equivalencia de los daños y perjuicios ocasionados ${ }^{80}$.

\section{Planteamiento Del dilema y propuesta}

Frente a este problema hay tres respuestas: $i)$ Una primera económicamente eficiente y moralmente neutra que defiende siempre y como regla (con escasas excepciones) la alternativa por equivalente o pecuniaria (sistemas del "common law" e italiano, antes de la reforma del 2009 al CPC. que incorporó las “astreintes") ${ }^{81}$; ii) Una segunda según la cual el acreedor es el soberano para exigir siempre y en primer término la vía primaria in natura y solo en subsidio las otras, que el ordenamiento le confiere, en cuyo subsidio se da la reparatoria por equivalencia, salida no tan eficiente económicamente, pero sí correcta moralmente (es el modelo tradicional del "civil law" con la fuerza de la influencia del "nemo praecisi coegit ad factum" del artículo $1142 \mathrm{CCFr}^{82}$ ) a varios países de esa tradición ${ }^{83}$; iii) finalmente existe una tercera salida que es la que se propone aquí, la que se considera económicamente más eficiente y correcta moralmente, es que el acreedor tenga la "opción” para escoger li-

${ }^{80}$ Riehm, Thomas, cit. (n. 2), pp. 15 ss.

${ }^{81}$ Visión de Farnsworth, E. Allan, Damages and Specific Relief (1979), pp. 247 253; Sloof, Randolph - Oosterbeek, Hessel - Sonnemans, Joep, On the Importance of Default Breach Remedies (2007), p. 163 (donde se dice que: "parties often remain loyal to the default remedies because they fail to agree about possible alternatives"); Ulen, Thomas, The Efficiency of Specific Performance,. Towards a Unified Theory of Contract Remedies, en Michigan Law Review, 83 (1984), pp. 341-343: "the bulk of the scholarship on efficient remedies has concerned the award of money damages, and a consensus has been reached on the form of damages that is most likely to promote economic efficiency".

${ }^{82}$ Sobre los orígenes del brocardo y su influencia actual, véase: Dondorp, Harry, "Precise cogi". Enforcing Specific Performance in Medieval Legal Scholarship, en HaLLebeek, Jan - Dondorp, Harry (editores), The Rigth to Specific Performance. The Historical development (Antwerp, 2010), pp. 21-53; SEFTON-Green, Ruth, French and English Crypto-Nationalism and European Private Law, en European Review of Contract Law, 8 (2012), p. 260.

${ }^{83}$ España, Francia, Alemania antes de la reforma al derecho de las obligaciones en 2002. Ortells Ramos, Manuel, La ejecución de condenas no dinerarias en la Ley de Enjuiciamiento Civil (Madrid, 2005), pp. 10-50; Pardo Iranzo, Virginia, Ejecución de sentencias por obligaciones de hacer y de no hacer (Valencia, 2001), pp. 15-40; OosTERHUIS, Janwillem, Industrialization and Specific Performance in the German Territories During the 19th Century, en Hallebeek, Jan - Dondorp, Harry (editores), The Rigth to Specific Performance. The Historical Development, (Antwerp, 2010) pp. 97133; Laithier, Yves-M., Comparative Reflections on the French Law of Remedies for Breach of Contract, en CoHen, Nili - McKendrick, Ewan (editores), Comparative Remedies for Breach of Contracts (Oxford, 2005), pp. 103-122. 
bremente entre la salida i) y la ii) según el mejor interés del acreedor siempre que sea tolerable o soportable por el deudor (no esté sujeto a imposibilidad), en esta propuesta no habría una salida impuesta sino salidas opcionales ${ }^{84}$.

En esta tercera propuesta no hay remedio primario y secundario, sino alternativas a un mismo nivel ${ }^{85}$. Es posible sostener la unidad del sistema de incumplimiento y la necesaria reformulación de los remedios ${ }^{86}$. Un precepto donde quizás la fuente se explicita vinculada al efecto del incumplimiento de una obligación es el artículo 1489 del CCCh. No resulta acá inocua la influencia del "nemo praecisi cogit ad factum" del artículo 1142 CCFr. Los artículos 1553 y $1555 \mathrm{CCCh}$. reconocen la opción a favor del acreedor entre el cumplimiento específico y la indemnización de daños. Es doctrinariamente que se distingue si la obligación de hacer es fungible, o no. Ello para que sea el acreedor quien en definitiva pueda optar por dos remedios: la ejecución

${ }^{84}$ En cierta medida lo sostenido por Hevia, Martín, Reasonableness and Responsabilitity. A Theory of Contract Law (Dordrecht, 2013), pp. 103-114 y 67-89; DePOoRTER, Ben - Tontrup, Stephan, How Law Frames Moral Intuitions. The Expressive Effect of Specific Performance, en Arizona Law Review, 54 (2012), p. 673; López Díaz, Patricia, La indemnización compensatoria por incumplimiento de los contratos bilaterales como remedio autónomo en el derecho civil chileno, en Revista chilena de Derecho Privado, 15 (2010), pp. 65-113.

${ }^{85}$ Siguiendo a Kreitner, cit. (n. 15), pp. 19-49.

${ }^{86}$ En Portugal, Lebre de Freitas, José, $A$ acção executiva (5ª edición, Coimbra, 2009). En la visión procesal francesa, Piedélievre, Stéphane, Droit de lexécution (Paris, 2009), pp. 157 ss. En Bélgica, WÉRY, Patrick, Les povoirs du judge en matière de contetieux contractuel, dans les principes du droit européen du contrat, en Liber Amicorum Jean-Pierre de Bandt (Bruxelle, 2004), pp. 707-736. En Alemania, Repgen, cit. (n. 28), pp. 13-40; у Zнао Xiuju, Nicht-Geldvollstreckung in Deutschland, England und China (Hamburg, 2008), pp. 10-25. En Holanda, HaAs, Daniel - JANSEN, Chris, Specific Performance in Dutch law, in Smits, Jan - HaAs, Daniel - Hesen, Geerte, Specific Performance in Contract Law, National and other Perspectives (Portland, 2008), pp. 11-29. En Italia, Рroto Pisani, Andreas, L'effetività dei mezzi di tutela giurisdizionale con particolare riferimento all attuazione della sentenza di condanna, en Rivista di Diritto Processuale (1975) 4; Salettri, Achille, 614bis. Attuazione degli obblighi di fare infungibile o di non fare, en SALETTI, Andreas - SASSANi, Bruno (editores), Commentario a la Riforma (Torino, UTET, 2009), pp. 192-205; TARUffo, Michelle, L'attuazione esecutiva dei diritti, profili comparatistici, en Rivista Trimestrale di Diritto e Procedura Civile (1988), p. 142; TREglia, Giorgio, L'attuazione dei provvedimenti, en Saletti, Achille - Tarzia, Guiseppe (editores), Il processo cautelare (Milano, Cedam, 2008), pp. 572-576. En el ámbito del derecho comunitario, véanse: DíEz-PiCAso Y PONCE DE LEÓn, Luis y otros, Los principios del derecho europeo de los contratos (Madrid, 2002), pp. 350-353; Lando, Henrik - Rose, Kaspar, On the Enforcement of Specific Performance in Civil Law Countries, en International Review of Law and Economics (2004), p. 473; WÉRY, cit. (n. 86), pp. 707-736; WÉrY, Patrick, Droit des obligations, I : Théorie générale du contrat (Bruxelles, 2010), pp. 435-444. 
forzosa y la indemnización de perjuicios, porque podría compeler al deudor a cumplir, aceptar que un tercero realice el hecho o pedir la indemnización de perjuicios. Ahora bien la visión expuesta funda la calificación de fungibilidad o infungibilidad en dos premisas: en primer lugar, se atiende a la específica función de la obligación dentro del tráfico jurídico, finalmente considera prioritario el interés del acreedor que debe ser satisfecho ${ }^{87}$. Coherente con ello la posibilidad de sustituir o intercambiar su objeto sólo será posible si no se ve lesionada la efectiva satisfacción del interés del acreedor, siendo esto el aspecto esencial para aplicar la proporcionalidad y examinar cuán tolerable le resulta la opción al deudor ${ }^{88}$.

Es así que conviven un sistema sustantivo-procesal que permite al acreedor optar, pero curiosamente al no establecer un orden de preferencia, no se garantiza el cumplimiento específico ni menos el derecho de opción de aquello que satisface su interés. Muy por el contrario la ejecución en el Código de Procedimiento Civil chileno tiene un sistema de incentivos negativos y positivos que finalizan transfiriendo al deudor la opción y decisión sobre cómo se efectivizará la prestación que se está ejecutando. Ahora si se reunifica la visión sustantiva-procesal de la tutela ejecutiva del crédito como parte del derecho de acción y se reconoce el rol relevante de la función jurisdiccional ejecutiva para la satisfacción específica, los medios para lograrlo deben adecuarse. Tanto la ejecución como los órganos predispuestos por el Estado para el ejercicio de esta función asumen un rol protagónico de efectivización y disuasión dentro de las relaciones de circulación del mercado. Si se parte de

${ }^{87}$ BARAHONa GonZÁLEZ, Jorge, Responsabilidad contractual y factores de imputación de daños, apuntes para una relectura en clave objetiva, en Revista Chilena de Derecho, 24 (1997) 1, pp. 151-177; VIdal Olivares, Álvaro, El incumplimiento de obligaciones con objeto fungible y los remedios del acreedor afectado. Un intento de relectura de las disposiciones del Código Civil sobre incumplimiento en Guzmán Brito, Alejandro (editor), Estudios de derecho civil (Santiago, 2008), III; Vidal Olivares, Álvaro La carga de mitigar las pérdidas del acreedor y su incidencia en el sistema de remedios por el incumplimiento, en Guzmán Brito, Alejandro (editor), El Código Civil de Chile. 1855-2005 (Santiago, 2008), pp. 429- 457; Vidal Olivares, Álvaro, La noción del incumplimiento esencial en el Código Civil, en Revista de Derecho de la Pontificia Universidad Católica de Valparaiso, 32 (2009) 1, pp. 226- 237.

${ }^{88}$ STÜRNER, Michael, Der Grundsatz der Verhältnismässigkeit im Schuldvertragsrecht (Tübingen, 2010), pp. 193-207; sustentando ello ética y económicamente: FrIEDman, Daniel, Rights and Remedies, en COHEN, Nili - McKendrick, Ewan (editores), Comparative Remedies for Breach of Contracts (Oxford, 2005), pp. 3-17; y EISENBERG, Actual and Virtual Specific Perfomance. The Theory of Efficient Breach and the Indifference Principle in Contract Law, en California Law Review, 93 (2005), p. 975. Para una noción detallada de imposibilidad véase: Brantt Zumarán, María Graciela, El caso fortuito y su incidencia en el derecho de la responsabilidad civil contractual, concepto y función del caso fortuito en el Código Civil chileno (Santiago, 2010). 
un deber general de cumplir los mandatos judiciales en las distintas etapas procesales y cualquiera que sea su naturaleza, el sistema procesal debe prever una serie de mecanismos para tutelar este deber general, sancionando su infracción con herramientas adecuadas para la disuasión y cumplimiento ${ }^{89}$.

Con corrección se estiman procedentes la aplicación de medidas tendientes a coaccionar la voluntad de quien se niega a cumplir ${ }^{90}$. Negar aplicación a las medidas coercitivas por el sólo hecho de existir la posibilidad de recurrir a la ejecución forzada, ya que ello implica atribuir a estas medidas un carácter subsidiario y por ende sin utilidad práctica parece no ser un argumento convincente. Por el contrario junto a la necesidad de una adecuada ejecución se vislumbra la necesidad de revestirla de eficacia. Así las medidas coercitivas toman un rol anexo y necesario para el ejercicio de la función jurisdiccional, especialmente ejecutiva ${ }^{91}$. Por cierto esta idea ya era vislumbrada en el derecho chileno siendo consideradas como anexas al éxito posible de la ejecución ${ }^{92}$. El sistema del actual Código de Procedimiento Civil chileno, no considerando las sentencias declarativas y constitutivas -como no hacemos aquí- deja en definitiva siempre la última palabra en las obligaciones no dinerarias al deudor quedando al final identificada de hecho la sentencia de condena con el equivalente pecuniario. ${ }^{93}$ Como en otros modelos comparados este régimen es aplicable supletoriamente a otros ámbitos desde la litigación civil, de familia, laboral y económica, hasta la pública, ambiental y de tutela de derechos fundamentales. Áreas en las que resulta a priori complejo pensar solo en la

${ }^{89}$ Proto Pisani, Andrea, El principio de efectividad en el proceso civil italiano, en PRIORI, G. editor), Efectividad y ejecución de las resoluciones judiciales (Lima, 2014), pp. 15 ss.

${ }^{90}$ Delebecque Philippe, L'exécution forcé, en Revue des Contrats (2006), pp. 99103; JACOBSON, Ulla - JАСОВ, Jack, Trends in the Enforcement of Non-Money Judgements and Orders (Antwerp, 1988), pp. 7-102.

${ }^{91}$ Kennet, Wendy, The Enforcement of Judgements in Europe. Non-Money Judgement (reimpresión, Oxford, 2005), pp. 287 ss.; Kerameus, Konstantinos, Enforcement Proceedings, en International Encyclopedia of Comparative Law. Civil Procedure (Tübingen, 2002), XVI, pp. 94-102; KerameUs, Konstantinos, Enforcement of NonMoney Judgements and Orders in a Comparative Perspective, en NAFZIGER, James - SYMEONIDES, Simon (editores), Law and Justice in a Multistate World, Essays in Honor of Arthur von Mebren (New York, 2002), pp. 107-119; Donniert, Marc - DonNIERT, Jean-Baptiste, Vois d'execution et procedures de distribution (Paris, 2008), pp. 52-58, 71-81 y 121-143.

${ }^{92}$ Lo que ya fuera vislumbrado por Fueyo LANERI, Fernando, Cumplimiento e incumplimiento de las obligaciones (Santiago, 2004), p. 216.

93 "Mensaje" No 398/357, de 16 de mayo de 2009 que inicia proyecto de ley que aprueba nuevo Código Procesal Civil; Orellana Torres, Fernando, Medios de impugnación y recursos procesales en la ejecución de condenas no dinerarias, en Ius et Praxis, 12 (junio de 2006) 2, pp. 163-200. 
salida pecuniaria o de satisfacción por equivalente, cuando los valores del interés del acreedor (muchas veces la Sociedad o las llamadas generaciones futuras) no toleran siempre esa salida optada (impuesta) por el deudor ${ }^{94}$.

Las condiciones del tráfico hoy en día han cambiado: existe un mercado abierto y diversificado que se expande cada día más; en él, escasean las obligaciones específicas no fungibles lo que se facilitan por las alternativas igualmente válidas para ser satisfechas, ya que el objeto fungible que las integra lo permite. Ello tanto en las obligaciones positivas tradicionales de dar una cosa, de hacer o realizar una prestación de servicio u obra. Es decir la opción para el acreedor no siempre es una indemnización (sustitutiva del objeto de su crédito), sino que su interés puede ser satisfecho en especie o natura, entendido ello como aquello que satisface el interés del acreedor según sus expectativas pasadas actuales y futuras ${ }^{95}$. Ese interés de satisfacción in natura podrá ser contrapuesto al del deudor, cuando éste se vea excedido proporcionalmente por el cumplimiento específico, siendo que le ocasiona un perjuicio superior al que le causaría la mitigación por equivalente pecuniario o sustitutivo del derecho interés del acreedor. Una obligación será en esta visión fungible cuando su objeto sea recíprocamente sustituible por otro, sin lesionar la efectiva satisfacción del interés del acreedor; en ellas, la posibilidad de satisfacción no es única, sino que las hay tantas como disponibles en el mercado. Correlativamente, la obligación será una con objeto no fungible, o específico, cuando la posibilidad de satisfacción del interés del acreedor sea única: sólo esa cosa determinada o la actividad que despliegue ese deudor, son idóneas para este fin.

Además surgen nuevos derechos como los de las relaciones de consumo, intereses supraindividuales y difusos en materia ambiental, libre competencia, protección de derechos industriales, de autor, marca y patente, salud, derechos en las relaciones y derecho de familia y otras donde el cumplimiento específico puede traducirse en una conducta positiva o negativa: en tanto un hacer, como un no hacer, cesar o tolerar no obstando una conducta ajena. En estos casos normalmente la fungibilidad del objeto no es simple de determinar, los costos para ambos interesados (muchos que surgen de relaciones extracontractuales) son elevadas: $i$ ) el acreedor podría sufrir un perjuicio de difícil o imposible reparación de no llevarse adelante la conducto exigida del deudor; el deudor podría sufrir un menoscabo mayor al equivalente pecuniario de su prestación; ii) En estos casos además la mensurabilidad

${ }^{94}$ Cruz Arenhart, Sergio, A tutela coletica de interesses individuais, en Revista dos Tribunais (San Pablo, 2013), pp.10-30; PÉREZ DEl Blanco, Gilberto La ejecución forzosa de sentencias en el orden jurisdiccional contencioso-administrativo (León, 2003), pp. 25-35.

${ }^{95}$ Proto Pisani, cit. (n. 86). 
dineraria como sustituto no resulta ni fácil ni fidedigna; iii) a lo que se suma que las relaciones se dan en ámbitos con mercados y situaciones reguladas e importante de políticas públicas.

\section{Conclusiones}

De la judicialización y eventual reconocimiento de esos derechos, se plantea la interrogante de cómo proceder a su cumplimiento, en caso que el deudor condenado no satisfaga voluntaria, íntegra e idénticamente (si corresponde) el crédito. Y en la ejecución es donde muchas veces hay disonancia entre lo sustantivo y lo obtenible por la vía ejecutiva. Solo considerar que el Código de Procedimiento Civil en la ejecución resulta aplicable supletoriamente a los otros ámbitos mencionados supra (libre competencia, ambiental, derecho intelectual, familia) y que su modesta como escueta regulación que distingue solo entre obligaciones de dar (dinerarias, las que no se analizan acá) o una cosa diferente a dinero (mueble o inmueble) y las obligaciones de hacer y no hacer, no parece adecuada a los tiempos actuales. En las positivas o negativas de conducta, la elección final sobre cumplimiento in natura o por equivalente pesa sobre el deudor, salvo casos donde el propio legislador optó por un sistema de sustitución por ficción de la voluntad del deudor por la del juez, en los casos de otorgamiento de actos jurídicos y constitución de derechos o en la ejecución directa para hacer entrega de una cosa (o cuerpo cierto). En relación a las conductas exigidas dentro de un proceso y que no se identifican con las obligaciones sustantivas, al interés del acreedor se suma la funcionalidad misma del proceso en donde se deben barajar las distintas alternativas sin olvidar que una podría ser su ejecución en especie. Estas conductas por lo tanto serán o no fungibles dependiendo de la necesidad objetiva que tengan para el proceso, sea esta determinada por el legislador directamente o habiendo intervenido la labor del juez en su fijación. Más si se tiene en cuenta que no siempre el interés del acreedor debiera revestir un carácter pecuniario (daño ambiental, discriminación, derechos personalísimos) y que ameritan un remedio específico sustantivo y un adecuado engranaje procesal ejecutivo en caso de conducta no cooperativa del deudor.

Por un lado en las relaciones contractuales que mencionáramos como un ámbito de aplicación de estas observaciones, se ocupa de la organización, regulación y la ulterior satisfacción de los intereses de las partes; éstas, al contratar, buscan la consecución de un propósito práctico que se alcanzará a través de la ejecución del contrato, propósito que interesa en la medida que se hubiere incorporado, explícita o implícitamente, a la regla contractual. Tal propósito práctico, integrado al contrato, permite al intérprete delinear para cada caso el interés del acreedor, el "interés contractual", que 
el contrato hace objeto de su protección. Por su parte en el ámbito de los nuevos derechos y la responsabilidad extracontractual el interés del acreedor también reviste ciertas particularidades en casos donde no podría sino ser satisfecho de una forma diferente a la resarcitoria o por equivalente. Esta solución frente al incumplimiento, en la práctica es la principal, porque eso es lo que al acreedor le interesa. Por ejemplo en las obligaciones de hacer, el artículo $1553 \mathrm{CCCh}$. otorga tres opciones al acreedor: ejecución forzada, y las dos siguientes por equivalente (las dos primeras son de ejecución in natura y la tercera por equivalente). Cuando el mismo tema se analiza a la luz del Código de Procedimiento Civil chileno, éste se hace cargo en detalle de los procedimientos de ejecución forzosa, de las obligaciones de dar, hacer o no hacer. En estas últimas distinguiendo si son o no personalísimas y en definitiva brindando la salida del equivalente pecuniario casi supeditado exclusivamente a la voluntad del deudor.

Las opciones rectoras del acreedor se sopesan según su razonabilidad con las posibilidades reales del deudor. Estas visiones enfrentadas se replican en el derecho comparado y las distintas visiones según la familia jurídica que se estudie. Curiosamente se reproduce el debate histórico que se desarrolló como núcleo de este trabajo.

\section{BIBLIOGRAFÍA}

Acollas, Emile, Manuel de Droit Civil (Paris, 1869)

Andrews, Neil - Clarke, Malcolm - Tetenborn, Andrew - Virgo, Grahan, Contractual Duties, Specific Relief, The Grant of Specific Perfomance (London, 2011).

Association H. Capitant (editora), Termnologie contractualle commune (Paris, 2008). Aтiyan, Patrick, The Liberal Theory of Contract, in Essays on Contract (Oxford, 1988). BARAHONA GONZÁlez, Jorge, Responsabilidad contractual y factores de imputación de daños, apuntes para una relectura en clave objetiva en Revista Chilena de Derecho, 24 (1997) 1.

BrantT Zumarán, María Graciela, El caso fortuito y su incidencia en el derecho de la responsabilidad civil contractual, concepto y función del caso fortuito en el Código Civil chileno (Santiago, 2010).

BRINZ, Alois von, Lehrbuch der Pandekten (Erlangen, 1879)

Brinz, Alois von, Obligation und Haftung, en Archiv für die Civilistische Praxis, 70 (1886).

Brooks, Richard W. (2006), The Efficient Performance Hypothesis, en Yale Law Journal, 116 (2006).

Cruz Arenahrt, Sergio, A tutela coletiva de interesses individuais (San Pablo, Revista dos Tribunais, 2013).

Delebeclue, Philippe, L'exécution forcé, en Revue des Contrats, 2 (2006).

Depoorter, B. - Tontrup, S., How Law Frames Moral Intuitions, the Expressive Effect of Specific Performance, en Arizona Law Review, 54 (2012). 
Diez-Picazo y Ponce de León, Luis y otros (editores), Los principios del derecho europeo de los contratos (Madrid, 2002).

Dilcher, Hermann, Geldkondemnation und Sachkondemnation in den mittelalterlichen Rechtstheorie, en Zeitschrift der Savigny-Stiftung für Rechtsgeschichte, Rom. Abt., 78 (1961).

Dilcher, Hermann, Die Theorie der Leistungsstörungen bei Glossatoren, Kommentatoren und Kanonisten (Frankfurt a. Main, 1960).

Dомат, Jean Les lois civile dans leur ordre naturel (Paris - Luxemburg, 1702), I.

Dondorp, Harry, "Precise Cogi", Enforcing Specific Performance in Medieval Legal Scholarship, en Hallebeek, Jan - Dondorp, Harry (editores), The Rigth to Specific Performance. The Historical Development (Antwerp, 2010).

Dondorp, Harry, Specific Performance, A Historical Perspective, en Smit, Jan - HaAs, Daniel - Hesen, Geerte (editores), Specific Performance in Contract Law, National and other Perspectives (Antwerp, 2010).

Donnier, M. - Donniert, J.B., Vois d'execution et procédures de distribution (Paris, 2008).

Eisenberg, M., Actual and virtual Specific Performance, the Theory of Efficient Breach, and the Indifference Principle in Contract Law, en California Law Revoew, 93 (2005).

Farnsworth, Allan, Damages and Specific Relief, en American Journal of Comparative $\operatorname{Law}(1979)$.

Friedman, Daniel, Rights and Remedies, en Cohen, N. - McKendrick, E. (editores), Comparative Remedies for Breach of Contracts (Oxford, 2005).

Fueyo Laneri, Fernando, Cumplimiento e incumplimiento de las obligaciones (Santiago, 2004).

Gómez Pomar, Fernando, El incumplimiento contractual en el derecho español en Revista para el análisis del Derecho, InDret, 3 (2007).

HaAs, D. - Jansen, C., Specific Performance in Dutch Law, en Smits, J. - HaAs, D. Hesen, G., Specific performance in Contract Law, National and other Perspectives (Antwerp, 2008).

Hallebeex, Jan - Dondorp, Harry, The Rigth to Specific Performance. The Historical Development (Antwerp, 2010).

Hardy, Robert, Punitive Damages for Certain Categories of Breaches of Contract? en Meurkens, L. - Nordin, E. (editores) The power of Punitive Domages (Antwerp, 2012).

Hartmann, Gustav, Die Obligation-Untersuchungen über ibren Zweck und Bau (Erlangen, 1875).

Hevia, Martín, Reasonableness and Responsabilitity. A Theory of Contract Law (Dordrecht, 2013).

Himmelschein, Jury, Erfüllungszwang und Lehren von den positiven Vertragsverletzungen, en Archiv für die Zivilistische Praxis, 135 (1932).

JАСОВ, Sir Jack, The Fabric of English Justice (London, 1887).

JACOBSON, U. - Јасов, J., Trends in the Enforcement of Non-Money Judgements and Orders (Antwerp, 1988).

JаковS, Horst, Unmöglichkeit und Nichterfüllung (Bonn, 1969)

KASER, Max, Römisches Zivilprozessrecht (München, 1966)

Kennet, Wendy, The Enforcement of Judgements in Europe. Non-money Judgement (Oxford, 2000 Reimp. 2005).

Kerameus, Konstantinos, Enforcement of Non-Money Judgements and Orders in a Com- 
parative Perspective, en Nafziger, J. - Symeonides, S. (editores), Law and Justice in a Multistate World. Essays in Honor of Arthur von Mehren (New York, 2002).

Kerameus, Konstantinos, Enforcement Proceedings, International Encyclopedia of Comparative Law-Civil Procedure (Tübingen, 2002), XVI.

KNütel, Christian, Die Schwächen und der "konkreten" und "abstrakten" Schadensberechnung und daspositive Interesse bei der Nichtserfüllung, en Archiv für die Zivilistische Praxis, 135 (2002).

KoHler, Josef, Ungehorsam und Vollstreckung im Civilprozeß, en Archiv für die Civilistische Praxis, 80 (1893).

Kovac, Mitja, Comparative Contract Law And Economics (Camberley, 2011).

Kreitner, Roy, Multiplicity in Contract Remedies, en Cohen, N. - MCKendrick, E. (editores), Comparative Remedies for Breach of Contracts (Oxford, 2005).

LAITHIER, Yves-Marie, Etude comparative des sanctions de linexécution du contrat (Paris, 2004).

LAITHIER, Yves-Marie, Comparative Reflections on the French Law of Remedies for Breach of Contract, en CoHen, N. - MCKendrick, E. (editores), Comparative Remedies for Breach of Contracts (Oxford, 2005).

Lando, H. - Rose, C., On the Enforcement of Specific Perfomancen Civil Law Countries, en International Review of Law and Economics (2004).

Lebre De Freitas, José, $A$ Acção Executiva (5a edición, Coimbra, 2009).

LiEBs, Detlev, Römisches Recht (Göttingen, 1982).

López DíAz, Patricia, La indemnización compensatoria por incumplimiento de los contratos bilaterales como remedio autónomo en el derecho civil chileno, en Revista Chilena de Derecho Privado, 15 (2010).

LuIg, Klaus, Wissenschaft und Kodifikation des Privatrechts im Zeitalter der Aufklärung in der Sichtvom Christian Thomasius, en Festschriftf. Helmut Coing (München, 1982), I.

Meagher - Gummow - Leahne, Equity, Doctrine and Remedies (4a edición, London, 2009).

Mensaje $\mathrm{N}^{\circ}$ 398/357 de 18 de mayo de 2009. Que inicia proyecto de ley que aprueba nuevo Código procesal civil

Moreno Quesada, B., Problemática de las obligaciones de hacer, en Revista de Derecho Privado (1976).

Mugdan, Benno, Die gesammten Materialien zum Bürgerlichen Gesetzbuch für das Deutsche Reich (Berlin, 1899).

NeHLSEn von STRYK, Karin, Grenzen des Rechtszwangs, Zur Geschichte der Naturalvollstreckung, en Archiv für die Civilistische Praxis, 193 (1993).

Oosterhuis, Janwillem, Industrialization and Specific Performance in the German Territories During the 19Th. Century, en Hallebeek, Jan - Dondorp, Harry (editores), The Rigth to Specific Performance. The Historical Development (Antwerp, 2010).

Orellana Torres, Fernando. Medios de impugnación y recursos procesales en la ejecución de condenas no dinerarias, en Ius et Praxis, 12 (Junio de 2006) 2.

Ortells Ramos, Manuel, La ejecución de condenas no dinerarias en la ley de Enjuiciamiento Civil (Madrid, 2005).

Pardo Iranzo, V., Ejecución de sentencias por obligaciones de hacer y de no hacer (Valencia, 2001)

Parisi, Francesco - Cenini, Marta - Luppi, Barbara, Enforcing Bilateral Promises, $A$ Comparative Law and Economics Perspective (Minnesota, 2014). 
Peñailillo Arévalo, Daniel, Obligaciones. Teoría general y clasificaciones. La resolución por incumplimiento (Santiago, 2003).

Pérez Del Blanco, M. La ejecución forzosa de sentencias en el orden jurisdiccional contencioso-administrativo (León, 2003).

Piedelièvre, Stéphane, Droit de lexécution (Paris, 2009).

Pizarro Wilson, Carlos, Hacia un sistema de remedios al incumplimiento contractual en Guzmán Brito, Alejandro (editor), Estudios de Derecho Civil(Santiago, 2008), III.

Pothier, Robert-Joseph, Traité des obligations, en CEuvres de Pothier (Paris, 1818), III.

Proto Pisani, A., L'effetività dei mezzi di tutela giurisdizionale con particolare riferimento all attuazione della sentenza di condanna, en Rivista di Diritto Processuale (1975) 4.

Proto PIsAni, Andrea, Elprincipio de efectividad en el proceso civil italiano, en PrIORI, G. (editor), Efectividad y ejecución de las resoluciones judiciales (Lima, 2014).

Remien, Oliver, Rechtsverwirklichung durch Zwangsgeld (Tübingen, 1992).

REPGEN, Tilman, Vertragstreue und Erfüllungszwang in der mittelalterlichen Rechtswissenschaft (Padderborn, 1994).

Rienm, Thomas, Der Grundsatz der Naturalerfüllung (Tübingen, 2014).

Rowan, Solène, Remedies for Breach of Contract (Oxford, 2012).

RÜCKERT, Joachim, Leistungsstörungen und Juristenideologien heute und gestern. Ein problemgeschichtlicher Beitrag zum Privatsrecht im Europa, en Festschrift Kilian (Baden-Baden, 2004).

Saletti, Achille, 614bis Attuazione degli obblighi di fare infungibile o di non fare, en Saletti, A. - Sassani, B. (editores), Commentario a la Riforma (Torino, 2009).

Savigny, Friedrich Carl von, System des heutigen römischen Rechts, (Berlin, 1840-1849) 8 volúmenes.

SAvigny, Friedrich Carl von, Das Obligationenrecht als Theil des heutigen römischen Recht (Berlin, 185 - 1853).

Schulz, Fritz, Classical Roman Law (Oxford, 1951).

Sefton-Green, R., French and English Crypto-Nationalism and European Private Law, en European Review of Contract Law, 8 (2012).

Sintenis, Carl Friedrich Ferdinand, Was ist Gegenstand der Klagen aus Obligationibus ad faciendum überhaupt und der action emti im Besesonderen, en Zeitschrift für Civilrecht und Prozess, 11 (1838).

Sloof, S .- Oosterbeek, H. - Sonnemans, J., On the Importance of Default Breach Remedies, en Journal of Institutional and Theoretical Economics, 5 (2007) 163.

Smits, J. - HaAs, D. - Hesen, G., Specific Performance on Contract Law, Nacional and other Perspectives (Portland, 2008).

Sohm, Rudop - Mitteis, Ludwig - Wenger, Leopold, Institutionen-Geschichte und System des römischen Privatsrechts (Berlin, 1949).

Söllner, Alfred, Die causa im Kondiktionen-und Vertragsrecht des Mittelalters bei den Glossatoren, Kommentatoren und Kanonisten, Zeitschrift der Savigny-Stiftung für Rechtsgeschichte, Rom. Abt., 77 (1960).

SPRY, I., The Principles of Equitable Remedies (8a edición, London, 2010).

Stathopoulos, Michael, Probleme der Vertragsbindung und Vertragslösung in rechtsvergleichende Betrachtung, en Archiv für die Civilistische Praxis, 194 (1994).

STÖCKLI, Hubert, Synallagma im Vertragrecht (Zürich, 2008).

STÜRner, Michael, Der Grundsatz der Verhältnismässigkeit im Schuldvertragsrecht (Tübingen, 2010). 
TARuffo, Michelle, L'attuazione esecutiva dei diritti, profli comparatistici, en Rivista Trimestrale di Diritto e Procedura Civile (1988).

Treglia, Giorgio, L'attuazione dei provvedimenti, en Saletti, A. - Tarzia, G. (editores), Il processo cautelare (Milano, 2008).

Treitel, Guenter, Remedies for Breach of Contracts. A Comparative Account (Oxford, 1988)

ULEN, Thomas, The Efficiency of Specific Performance. Toward a Unified Theory of Contract Remedies, en Michigan Law Review, 83 (1984).

Vidal Olivares, Álvaro, Cumplimiento e incumplimiento contractual en el Código Civil. Una perspectiva más realista en Revista Chilena de Derecho, 34 (2007) 1.

Vidal Olivares, Álvaro, El incumplimiento de obligaciones con objeto fungible y los remedios del acreedor afectado. Un intento de relectura de las disposiciones del Código Civilsobre incumplimiento, en GuZMán Brito, Alejandro (editor), El Código Civil de Chile. 1855-2005 (Santiago, 2008).

VIDAl Olivares, Álvaro, La carga de mitigar las pérdidas del acreedor y su incidencia en el sistema de remedios por el incumplimiento en GUZMÁN BRITO, Alejandro (editor), Estudios de Derecho Civil (Santiago, 2008), III.

Vidal Olivares, Álvaro, La noción del incumplimiento esencial en el Código Civil en Revista de Derecho de la Pontificia Universidad Católica de Valparaíso, 32 (2009) 1.

Vogenauer, Stefan, en Cartwright, J. - Whittaker, S. - Vogenauer, S. (editores), Reforming the French Law of Obligation. Comparative Reflections - "AvantProjet de Réforme". An Overview (Oxford, 2009).

WAGNER, Gerhard, Ansprüche auf Unmögliches? en Juristen Zeitung (1998).

Weller, Marc-Philippe, Die Struktur des Erfüllungsanspruches im BGB, common law und DCFR-Ein kritischer Vergleich, en Juristen Zeitung (2008).

Weller, Marc-Philippe, Die Vertragstreue (Tübingen, 2009).

WÉRY, Patrick, Droit des Obligations, V,1: Théorie générale du contrat (Bruxelles, 2010).

WÉRY, Patrick, Lespovoirs du judge en matière de contetieux contractuel dans lesprincipes $d u$ droit européen du contrat, en Liber Amicorum Jean-Pierre de Bandt (Bruxelle, 2004).

Wéry, Patrick, Specific performance in Belgian Law, en SMITs, J. - Haas, D. - Hesen, G., Specific Performance in Contract Law, National and other Perspectives (Antwerp, 2008).

Wilhelmi, Rüdiger, Risikoschutz durch Privatrecht (Tübingen, 2009).

Windscheid, Bernhard, Die Actio-Abwehr gegen Dr. Theodor Muther (1857, reimpresión Aalen, 1969).

Windscheid, Bernhard - Kipp, Theodor, Lehrbuch des Pandektenrecht (Frankfurt a. M., 1906).

Windscheid, Bernhard Die Actio des römischen Zivilrechts vom Standpunkte des beutigen Rechts (1856, reimpresión Aalen, 1969).

ZhaO XIUju, Nicht-Geldvollstreckung in Deutschland, England und China (Hamburg, 2008).

ZIEBARTH, Karl, Realexecution und Obligations mit besonderer Rücksicht auf die Miethe erörtet nach römischen und deuschtem Recht im Vergleich mit dem preussischem (Halle, 1866).

Zimmermann, Reinhard, Law of Obligations (Oxford, 1996).

Zuckerman, Adrian, Civil Procedure (Oxford, 2003). 
